\title{
A Pseudodynamic Approach of Seismic Active Pressure on Retaining Walls Based on a Curved Rupture Surface
}

\author{
Zuofei Yan ${ }^{(D)},{ }^{1}$ Yahong Deng $\left(\mathbb{D},{ }^{1,2}\right.$ Jia He ${ }^{(D)},{ }^{1}$ You Xuan ${ }^{(D)},{ }^{1}$ and Wei Wu ${ }^{1}$ \\ ${ }^{1}$ Department of Geological Engineering, Chang'an University, Xi'an 710064, China \\ ${ }^{2}$ Key Laboratory of Mine Geological Hazards Mechanism and Control, Xi'an 710054, China \\ Correspondence should be addressed to Yahong Deng; dgdyh@chd.edu.cn
}

Received 14 September 2019; Accepted 21 December 2019; Published 14 February 2020

Academic Editor: Francesco Tornabene

Copyright (c) 2020 Zuofei Yan et al. This is an open access article distributed under the Creative Commons Attribution License, which permits unrestricted use, distribution, and reproduction in any medium, provided the original work is properly cited.

Reasonable determination of the magnitude and distribution of dynamic earth pressure is one of the major challenges in the seismic design of retaining walls. Based on the principles of pseudodynamic method, the present study assumed that the critical rupture surface of backfill soil was a composite curved surface which was in combination with a logarithmic spiral and straight line. The equations for the calculation of seismic total active thrusts on retaining walls were derived using limit equilibrium theory, and earth pressure distribution was obtained by differentiating total active thrusts. The effects of initial phase, amplification factor, and soil friction angle on the distribution of seismic active earth pressure have also been discussed. Compared to pseudostatic and pseudodynamic methods for the determination of planar failure surface forms, the proposed method receives a bit lower value of seismic active earth pressures.

\section{Introduction}

One of the major tasks in seismic designs is the determination of dynamic earth pressures on retaining walls during an earthquake which makes the development of a realistic seismic earth pressure theory essential. Based on static Coulomb earth pressure theory, Okabe [1] and Mononobe and Matsuo [2] conducted in-depth investigations on different forms of retaining wall failure modes during earthquakes and proposed equations for the calculation of seismic earth pressures on retaining walls, known as Mononobe-Okabe (M-O) or pseudostatic method. This method considers seismic load as a simple inertial force to take into account the dynamic nature of earthquake loadings in a very approximate way. Steedman and Zeng [3] proposed a pseudodynamic method to consider certain dynamic response characteristics in a relatively simple way. Their proposed method solved the problem of seismic earth pressures on retaining walls by taking into account the phase differences and amplification effects of seismic waves by assuming the critical fracture surface of the backfill as being planar. Zeng and Steedman [4] compared pseudodynamic analysis results with those obtained experimentally from a centrifuge model to verify the accuracy of the proposed theoretical method. In the pseudodynamic method proposed by Steedman and Zeng [3], simply shear wave velocity $\left(v_{\mathrm{s}}\right)$ and horizontal seismic acceleration $\left(k_{\mathrm{h}} g\right.$, where $g$ is the acceleration due to gravity) were considered. Choudhury and Nimbalkar [5] considered primary wave velocity $\left(v_{\mathrm{p}}\right)$ and vertical seismic acceleration $\left(k_{\mathrm{v}} g\right)$ based on the pseudodynamic method developed by Steedman and Zeng [3] to study the seismic earth pressures on retaining walls. Many other researchers have conducted detailed studies using the pseudodynamic method, assuming the failure surface of the backfill to be planar [6-10].

All the abovementioned methods assume the failure surface of backfill to be planar. Terzaghi et al. [11] found that the seismic earth pressure coefficients obtained by assuming flat rupture surfaces had large deviations from real values with calculation errors of up to 3 times higher than the real value. By assuming curved rupture surfaces, Kumar [12] deduced theoretical equations for the calculation of seismic earth pressures on the back of inclined retaining walls based on the pseudostatic method. It was found that the calculated 
seismic earth pressures were more reasonable when the critical rupture surface was assumed to be curved. Based on the pseudostatic method, Soubra [13], Choudhury et al. [14], and Subba Rao and Choudhury [15] assumed critical rupture surfaces as logarithmic spiral or a combination of logarithmic spiral and straight lines and derived theoretical equations for seismic earth pressures at different dip angles of retaining walls. Also, Basha and Babu [16-19] studied seismic structures using the pseudodynamic method by assuming curved critical rupture surface for backfill but did not obtain the distributions of seismic earth pressures along the depth of retaining walls. Xu et al. [20] applied the LSR (log-spiral-Rankine) model to assess active and passive seismic earth pressures and introduced local and global iteration schemes to solve the resulting highly coupled multivariate nonlinear system of equations, which was more complicated. Santhoshkumar et al. [21] computed the seismic active resistance of a slanted cantilever retaining wall holding a cohesionless backfill and did not assume a preordained failure mechanism.

To the best of our knowledge, seismic active earth pressure theory based on the pseudodynamic method by assuming curved rupture surfaces has not yet been developed. Therefore, in this study, we assumed composite curve critical rupture surface for backfill and investigated the effects of the phase difference and amplification of seismic waves, soil friction angle, soil-wall friction angle, horizontal seismic acceleration coefficient, and vertical seismic acceleration coefficient. According to limit equilibrium theory, we also deduced equations for the calculation of total seismic active thrusts on the walls and obtained the distributions of active earth pressures along the depth of retaining walls. The effects of the initial phase, soil amplification factor, and soil friction angle on the distribution of seismic active earth pressure had also been discussed. The obtained results were compared with previous studies where the distributions of seismic active earth pressure were obtained by pseudostatic and pseudodynamic methods under the assumption of planar rupture surfaces.

\section{Method of Analysis}

2.1. Basic Assumptions. Based on the principles of pseudodynamic method, in the present study, we have taken the following assumptions:

(a) The back of the retaining wall was vertical and the surface of backfill was horizontal

(b) The critical rupture surface of backfill was a combination of logarithmic spiral and straight line, and the rupture surface of the soil wedge passed through the heel of the retaining wall

(c) The shear modulus $G$ of backfill soil was constant along the wall

(d) Backfill was homogeneous, isotropic, dry, and noncohesive soil

(e) Zero-stress-boundary condition was neglected
Figure 1 shows the schematic diagram of a retaining wall calculation model based on the proposed method. As mentioned above, the back of the retaining wall was assumed to be vertical with height $H$ and backfill soil was considered to be noncohesive and the effects of amplification factor, soil friction angle, soil-wall friction angle, and horizontal and vertical seismic acceleration coefficients were taken into account. Under the action of horizontal and vertical seismic inertial forces, the horizontal and vertical seismic accelerations at any depth and any time were as follows:

$$
\begin{aligned}
a_{\mathrm{h}}(z, t) & =\left[1+\frac{H-z}{H}\left(f_{\mathrm{a}}-1\right)\right] k_{\mathrm{h}} g \sin \omega\left(t-\frac{H-z}{v_{\mathrm{s}}}\right) \\
& =\left[1+\frac{H-z}{H}\left(f_{\mathrm{a}}-1\right)\right] k_{\mathrm{h}} g \sin 2 \pi\left(\frac{t}{T}-\frac{H-z}{\lambda_{\mathrm{s}}}\right), \\
a_{\mathrm{v}}(z, t) & =\left[1+\frac{H-z}{H}\left(f_{\mathrm{a}}-1\right)\right] k_{\mathrm{v}} g \sin \omega\left(t-\frac{H-z}{v_{\mathrm{p}}}\right) \\
& =\left[1+\frac{H-z}{H}\left(f_{\mathrm{a}}-1\right)\right] k_{\mathrm{v}} g \sin 2 \pi\left(\frac{t}{T}-\frac{H-z}{\lambda_{\mathrm{p}}}\right) .
\end{aligned}
$$

The purpose of this study was to derive a series of equations to simplify the calculation of the distribution of seismic active earth pressure, similar to those in Rankine's earth pressure theory, M-O method, and Choudhury and Nimbalkar method [5]. Before this work, there was no report on equations for deriving seismic active earth pressure based on a curved rupture surface. Therefore, we only assumed one failure mechanism to simplify the calculation of seismic active earth pressure and fixed the focus of log-spiral curve at point " $O$ " under active seismic conditions.

2.2. Deducing Process. The force of soil wedge $O C B$ was first analyzed to obtain contact force $N_{2}$ between the wedges $O C B$ and $O A C$ (as shown in Figure 1). The mass of a thin element $(\mathrm{d} z)$ of the wedge $O C B$ at depth $z$ and the total weight of the soil wedge (shown in Figure 1(b)) were calculated by

$$
\begin{aligned}
m_{O C B}(z) & =\frac{\gamma}{g} l_{1}(z) \mathrm{d} z \\
& =2 \frac{\gamma}{g}(h-z) \cot \alpha \mathrm{d} z, \\
W_{\text {OCB }} & =\gamma h^{2} \cot \alpha .
\end{aligned}
$$

Horizontal and vertical seismic inertial forces of wedge $O C B$ were calculated as

$$
\begin{aligned}
Q_{\mathrm{h}, O C B}(t) & =\int_{0}^{h} m_{O C B}(z) a_{\mathrm{h}}(z, t), \\
Q_{\mathrm{v}, \mathrm{OCB}}(t) & =\int_{0}^{h} m_{O C B}(z) a_{\mathrm{v}}(z, t) .
\end{aligned}
$$




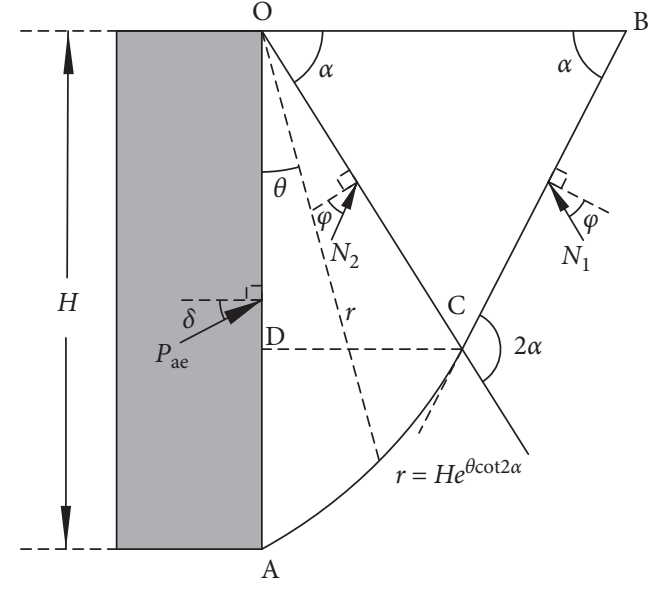

(a)

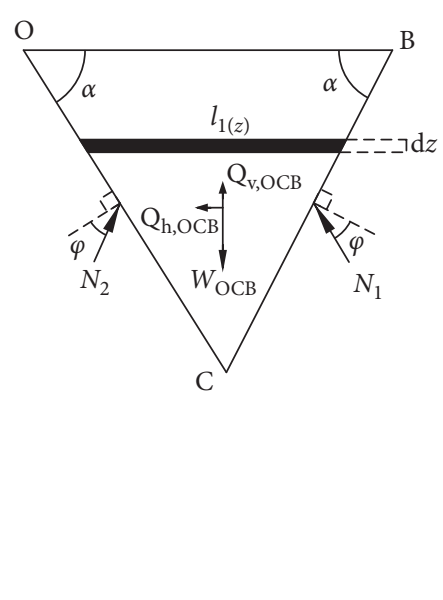

(b)
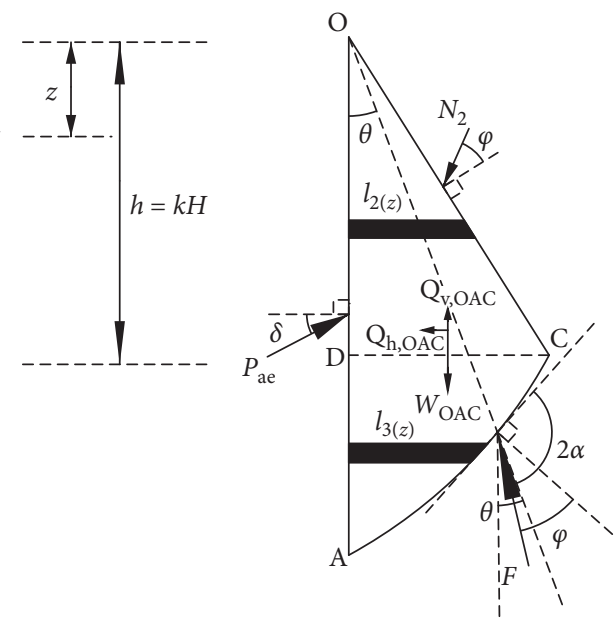

(c)

FIgURE 1: Schematic diagram of the retaining wall calculation model.

Contact force $N_{2}(t)$ could be obtained by calculating forces on wedge $O C B$ and considering the equilibrium of forces as

$$
N_{2}(t)=\frac{\left(W_{O C B}-Q_{\mathrm{v}, O C B}(t)\right) \sin (\alpha-\phi)+Q_{\mathrm{h}, \mathrm{OCB}}(t) \cos (\alpha-\phi)}{\sin (2 \alpha-2 \phi)} .
$$

Similarly, taking wedge $O A C$ as the mechanics case study (shown in Figure 1(c)), the masses of the thin elements of wedges $O D C$ and $D A C$ could be written as

$$
\begin{aligned}
& m_{O D C}(z)=\frac{\gamma}{g} l_{2}(z) \mathrm{d} z, \\
& m_{D A C}(z)=\frac{\gamma}{g} l_{3}(z) \mathrm{d} z .
\end{aligned}
$$

The total weights of wedges $O D C$ and $D A C$ could be expressed as

$$
\begin{aligned}
& W_{O D C}=\frac{1}{2} \gamma h^{2} \cot \alpha, \\
& W_{D A C}=\gamma \int_{h}^{H} l_{3}(z) \mathrm{d} z .
\end{aligned}
$$

Horizontal and vertical seismic inertial forces acting on wedges $O D C$ and $D A C$ were

$$
\begin{aligned}
Q_{\mathrm{h}, O D C}(t) & =\int_{0}^{h} m_{O D C}(z) a_{\mathrm{h}}(z, t), \\
Q_{\mathrm{v}, O D C}(t) & =\int_{0}^{h} m_{O D C}(z) a_{\mathrm{v}}(z, t), \\
Q_{\mathrm{h}, D A C}(t) & =\int_{h}^{H} m_{D A C}(z) a_{\mathrm{h}}(z, t), \\
Q_{\mathrm{v}, D A C}(t) & =\int_{h}^{H} m_{D A C}(z) a_{\mathrm{v}}(z, t) .
\end{aligned}
$$

Total seismic active thrust on the retaining wall could be obtained by resolving forces acting horizontally and vertically on wedge $O A C$ as follows.
Considering horizontal equilibrium condition $(\Sigma H=0)$ for wedge $O A C$,

$$
\mathrm{Q}_{\mathrm{h}, O A C}+N_{2} \sin (\alpha-\varphi)+F_{\mathrm{h}}=P_{\mathrm{ae}} \cos \delta
$$

Considering vertical equilibrium condition $(\Sigma V=0)$ for wedge $O A C$,

$$
W_{\mathrm{OAC}}+N_{2} \cos (\alpha-\varphi)=Q_{\mathrm{v}, \mathrm{OAC}}+P_{\mathrm{ae}} \sin \delta+F_{\mathrm{v}},
$$

where

$$
\begin{aligned}
W_{O A C} & =W_{O D C}+W_{D A C}, \\
Q_{\mathrm{h}, O A C} & =Q_{\mathrm{h}, O D C}+Q_{\mathrm{h}, D A C}, \\
Q_{\mathrm{v}, O A C} & =Q_{\mathrm{v}, O D C}+Q_{\mathrm{v}, D A C},
\end{aligned}
$$

where $F_{\mathrm{h}}$ and $F_{\mathrm{v}}$ can be estimated as

$$
\begin{aligned}
F_{\mathrm{h}} & =\int_{0}^{(\pi / 2)-\alpha} F \cos [\pi-(2 \alpha-\phi+\theta)] \mathrm{d} \theta \\
& =F[\sin (2 \alpha-\phi)-\cos (\alpha-\phi)], \\
F_{\mathrm{v}} & =\int_{0}^{(\pi / 2)-\alpha} F \sin [\pi-(2 \alpha-\phi+\theta)] \mathrm{d} \theta \\
& =F[\cos (2 \alpha-\phi)+\sin (\alpha-\phi)] .
\end{aligned}
$$

Solving equations (8) and (9), the total active thrust under seismic conditions could be obtained as

$$
\begin{aligned}
P_{\mathrm{ae}}(t)= & \frac{1}{\cos (2 \alpha-\delta-\phi)+\sin (\alpha-\delta-\phi)} \\
& \times\left\{N_{2}(t)[\sin (3 \alpha-2 \phi)-\cos (2 \alpha-2 \phi)]\right. \\
& +\left(W_{O A C}-Q_{\mathrm{v}, O A C}(t)\right)[\sin (2 \alpha-\phi)-\cos (\alpha-\phi)] \\
& \left.+Q_{\mathrm{h}, O A C}(t)[\sin (\alpha-\phi)+\cos (2 \alpha-\phi)]\right\} .
\end{aligned}
$$

Seismic active earth pressure coefficient $K_{\text {ae }}(t)$ was defined as 


$$
K_{\mathrm{ae}}(t)=\frac{2 P_{\mathrm{ae}}}{\gamma H^{2}} .
$$

To obtain the value of seismic active earth pressure coefficient, the height of wedge $O C B, h$, should be substituted by that of the retaining wall, $H$. The logarithmic spiral equation was used as follows:

$$
r=H e^{\theta \cot 2 \alpha} .
$$

From equation (14), we can relate $h$ to $H$ as follows:

$$
h=e^{((\pi / 2)-\alpha) \cot 2 \alpha} \times H=k H .
$$

According to Rankine's theory, for active case, the angle made by rupture surface and horizontal line could be obtained from $\alpha=45^{\circ}+(\varphi / 2)$. The maximum value of $K_{\mathrm{ae}}$ could be obtained by optimizing $K_{\mathrm{ae}}$ with respect to the initial phase of $t / T(0<t / T<1)$.

The distribution of seismic active earth pressure was obtained by differentiating total active thrust $P_{\text {ae }}(t)$ as

$$
\begin{aligned}
p_{\mathrm{ae}}(t)= & \frac{\partial P_{\mathrm{ae}}(t)}{\partial z} \\
= & \frac{1}{\cos (2 \alpha-\delta-\phi)+\sin (\alpha-\delta-\phi)} \\
& \times\left\{\frac{\partial N_{2}(t)}{\partial z}[\sin (3 \alpha-2 \phi)-\cos (2 \alpha-2 \phi)]\right. \\
& +\left(\frac{\partial W_{\mathrm{OAC}}}{\partial z}-\frac{\partial Q_{\mathrm{v}, O A C}(t)}{\partial z}\right)[\sin (2 \alpha-\phi)-\cos (\alpha-\phi)] \\
& \left.+\frac{\partial Q_{\mathrm{h}, O A C}(t)}{\partial z}[\sin (\alpha-\phi)+\cos (2 \alpha-\phi)]\right\}
\end{aligned}
$$

where

$$
\begin{aligned}
\frac{\partial W_{O A C}}{\partial z} & =\frac{\partial W_{O D C}}{\partial z}+\frac{\partial W_{D A C}}{\partial z} \\
& =\frac{\partial(\gamma / g) \int_{0}^{k z} l_{2}(\zeta) \mathrm{d} \zeta}{\partial z}+\frac{\partial(\gamma / g) \int_{k z}^{z} l_{3}(\zeta) \mathrm{d} \zeta}{\partial z} \\
\frac{\partial Q_{\mathrm{h}, O A C}}{\partial z} & =\frac{\partial Q_{\mathrm{h}, O D C}}{\partial z}+\frac{\partial Q_{\mathrm{h}, D A C}}{\partial z} \\
& =\frac{\partial \int_{0}^{k z} m_{O D C}(\zeta) a_{\mathrm{h}}(\zeta, t)}{\partial z}+\frac{\partial \int_{k z}^{z} m_{D A C}(\zeta) a_{\mathrm{h}}(\zeta, t)}{\partial z} \\
\frac{\partial Q_{\mathrm{v}, O A C}}{\partial z} & =\frac{\partial Q_{\mathrm{v}, O D C}}{\partial z}+\frac{\partial Q_{\mathrm{v}, D A C}}{\partial z} \\
& =\frac{\partial \int_{0}^{k z} m_{O D C}(\zeta) a_{\mathrm{v}}(\zeta, t)}{\partial z}+\frac{\partial \int_{k z}^{z} m_{D A C}(\zeta) a_{\mathrm{v}}(\zeta, t)}{\partial z}
\end{aligned}
$$

To give physical significance to the term " $\partial N_{2}(t) / \partial z$ " in the whole depth range of the retaining wall, the upper limit of integral was changed by the mathematical calculus method and the distribution of $N_{2}(t)$ within the depth range of $h$ was transformed into distribution within the depth range $H$ of the retaining wall (as shown in Figure 2) as

$$
\begin{aligned}
N_{2}(t)= & \frac{1}{\sin (2 \alpha-2 \phi)} \\
& \times\left\{\left(2 \frac{\gamma}{g} \cot \alpha \int_{0}^{k H}(k H-z) \mathrm{d} z-\int_{0}^{k H} m_{\mathrm{OCB}}(z) a_{\mathrm{h}}(z, t)\right)\right. \\
& \left.\cdot \sin (\alpha-\phi)+\int_{0}^{k H} m_{\mathrm{OCB}}(z) a_{\mathrm{v}}(z, t) \cos (\alpha-\phi)\right\} \\
& \underline{z=k \xi} \frac{1}{\sin (2 \alpha-2 \phi)} \\
& \times\left\{\left(2 \frac{\gamma}{g} \cot \alpha \int_{0}^{H}(k H-k \xi) k \mathrm{~d} \xi-\int_{0}^{H} m_{\mathrm{OCB}}(k \xi) a_{\mathrm{h}}(k \xi, t)\right)\right. \\
& \left.\cdot \sin (\alpha-\phi)+\int_{0}^{H} m_{\mathrm{OCB}}(k \xi) a_{\mathrm{v}}(k \xi, t) \cos (\alpha-\phi)\right\} \\
& \frac{1}{\sin (2 \alpha-2 \phi)} \\
& \times\left\{\left(2 \frac{\gamma}{g} \cot \alpha \int_{0}^{H} k^{2}(H-z) \mathrm{d} z-\int_{0}^{H} m_{O C B}(k z) a_{\mathrm{h}}(k z, t)\right)\right. \\
& \left.\cdot \sin (\alpha-\phi)+\int_{0}^{H} m_{\mathrm{OCB}}(k z) a_{\mathrm{v}}(k z, t) \cos (\alpha-\phi)\right\} . \\
& \\
&
\end{aligned}
$$

Finally, we got:

$$
\begin{aligned}
\frac{\partial N_{2}(t)}{\partial z}= & \frac{1}{\sin (2 \alpha-2 \phi)} \\
\times & \left\{\frac{2(\gamma / g) \cot \alpha \times \partial \int_{0}^{z} k^{2}(z-\zeta) \mathrm{d} \zeta}{\partial z}\right. \\
& \left.-\frac{\partial \int_{0}^{z} m_{O C B}(k \zeta) a_{\mathrm{h}}(k \zeta, t)}{\partial z}\right) \sin (\alpha-\phi) \\
& \left.+\frac{\partial \int_{0}^{z} m_{O C B}(k \zeta) a_{\mathrm{v}}(k \zeta, t)}{\partial z} \cos (\alpha-\phi)\right\} .
\end{aligned}
$$

Because the polar equation of logarithmic spiral could not be directly related to the rectangular coordinate equation, for the length of a thin element on wedge $D A C$, the solution given in this study used $\left\{1, x, x^{2}, x^{3}\right\}$ as the basis function (where $x=z / H$ ) for polynomial approximation under rectangular coordinates for polar coordinate equations. The function relationship between the length and 


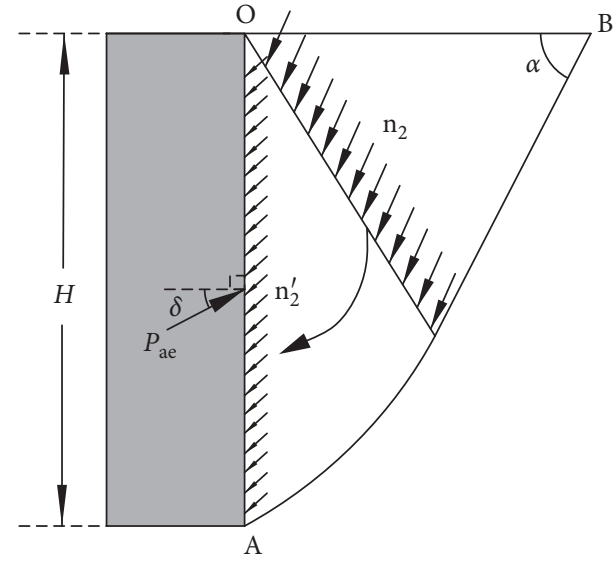

FIgURE 2: Schematic of distribution of $N_{2}$ along the entire height $H$ of the retaining wall.

depth of the thin element of logarithmic spiral (Table 1) could be expressed as

$$
r=H e^{\theta \cot 2 \alpha} \longrightarrow l_{3}=f(z) .
$$

\section{Analysis and Comparison of Effective Factors}

In this study, different parameters such as $H / \lambda_{s}=0.5$ and $H / \lambda_{p}=0.03$ have been used in the study of Maskar et al. [9], and these values do not represent actual values. The readers can substitute exact values according to actual situation. We have focused on the process and method of determining the distribution of active earth pressures on retaining walls under seismic conditions with curved failure surfaces. In the following simple analyses, the distributions and variations of earth pressure were determined considering the effects of initial phase $(t / T)$ change of seismic acceleration in one wave period, amplification factor $f_{\mathrm{a}}$, and soil friction angle $\varphi$. The effects of other seismic and backfill soil parameters on the distribution of soil pressure have not been discussed here. All calculations in this paper were carried out by MATLAB software [21].

3.1. Effect of Initial Phase ( $t / T)$. Figure 3 shows the distribution and variation of earth pressure along the depth $z$ of retaining wall with initial phase $(t / T)$ change in seismic acceleration in one wave period. Different initial phase $t / T$ values of $0,0.25,0.50$, and 0.75 were applied here, including when $K_{\mathrm{ae}}$ reached the maximum value $(t / T=0.60)$. As can be seen in Figure 3, the value of total active earth thrust in one period $P_{\mathrm{ae}}(t)$ was first increased and then decreased with the increase of $t / T$ (based on the area enclosed by the earth pressure distribution curve and coordinate axis). $K_{\mathrm{ae}}$ had its minimum value when $t / T=0.10$, and its maximum value was obtained when $t / T=0.60$. At the bottom of the retaining wall $(z / H=1)$, earth pressure was first increased and then decreased with time, reaching its maximum value when $t / T=0.50$. Earth pressure was approximately $59 \%$ of its maximum value when $t / T=0$. Since dynamic pressure was increased nonlinearly with depth, the position of dynamic thrust varied with time (Figure 3 ). When the earthquake occurs, the distribution of earth pressure changes with time (or phase) similar to the phenomenon is observed in this part. We took the time when the total active thrust reached its maximum value due to the critical seismic state of the retaining wall.

3.2. Effect of Amplification Factor $\left(f_{a}\right)$. To facilitate the analysis of the distribution of seismic active earth pressure with earthquake or soil parameters, the distribution of the earth pressure was the distribution when $K_{\mathrm{ae}}$ reaches its maximum value. Figure 4 shows the distribution of seismic active earth pressure along the depth of the retaining wall for different values of the amplification factor. As shown in Figure 4 , by changing the value of the amplification factor, the shape of the earth pressure distribution curve was slightly changed. By increasing the value of $f_{\mathrm{a}}$, total active earth thrust was also gradually increased. It was found that the maximum value of $K_{\mathrm{ae}}\left(K_{\mathrm{ae}}(t) \max \right)$ when $f_{\mathrm{a}}=1$ was approximately $84 \%$ of its corresponding value when $f_{\mathrm{a}}=2$. At the bottom of retaining wall $(z / H=1)$, the maximum value of earth pressure $\left(p_{\mathrm{ae}}(t) \max \right)$ when $f_{\mathrm{a}}=1$ was approximately $90 \%$ of its corresponding value when $f_{\mathrm{a}}=2$. This indicated that the vibration amplification effect of backfill had a relatively slight impact on seismic active earth pressure on the retaining wall. Therefore, to ensure the safety of the structure, vibration amplification effect of soil had to be taken into account while designing safe seismic structures.

3.3. Effect of Soil Friction Angle $(\varphi)$. Figure 5 shows the distribution of soil pressure along the depth of the retaining wall for different friction angles $\varphi$ of backfill soil. It can be clearly seen in the figure that the variation of friction angle $\varphi$ had a great effect on seismic active earth pressure on the retaining wall. The value of $K_{\mathrm{ae}}(t) \max$ when $\varphi=50^{\circ}$ was approximately $38 \%$ of its corresponding value when $\varphi=20^{\circ}$. At the bottom of the retaining wall $(z / H=1)$, the maximum value of earth pressure $\left(p_{\text {ae }}(t) \max \right)$ when $\varphi=50^{\circ}$ was about $32 \%$ of its corresponding value when $\varphi=20^{\circ}$. Therefore, it was concluded that selection of proper values for soil friction angle $\varphi$ was very important in seismic safe design since improper values could cause great calculation errors and ultimately affect the safety of retaining structures under seismic forces.

3.4. Comparison of Results. Figure 6 compares our results with those obtained from M-O (Mononobe-Okabe) and C-N (Choudhury-Nimbalkar) methods for the distribution of active earth pressure on a retaining wall under seismic conditions when $f_{\mathrm{a}}=1, k_{\mathrm{h}}=0.2, k_{\mathrm{v}}=0.5 k_{\mathrm{h}}, \phi=30^{\circ}$, $\delta=0.5 \phi, H / \lambda_{s}=0.5$, and $H / \lambda_{p}=0.03$. Like C-N method, the earth pressure distribution curve obtained in the study presented nonlinear characteristics. In general, based on pseudodynamic method, the maximum value of total active earth thrust calculated in this study for curved critical rupture surface was lower than that obtained from the C-N 
TABLE 1: Approximation of logarithmic spirals $\left(r=H e^{\theta \cot 2 \alpha}\right)$.

\begin{tabular}{cccccc}
\hline$\varphi$ & $\alpha$ & $k$ & Independent variables & Dependent variables & Cubic polynomials \\
\hline $20^{\circ}$ & $55^{\circ}$ & 0.655851 & & & $l_{3} / H=-5.098(z / H)^{3}+10.29(z / H)^{2}-7.732(z / H)$ \\
& & & & & +2.544 \\
$30^{\circ}$ & $60^{\circ}$ & 0.640094 & & & $l_{3} / H=-1.782(z / H)^{3}+2.908(z / H)^{2}-2.144(z / H)$ \\
& & & $z / H(=(r / H) \cos \theta)$ & $l_{3} / H(=(r / H) \sin \theta)$ & +1.018 \\
$40^{\circ}$ & $65^{\circ}$ & 0.628448 & & & $l_{3} / H=-0.5583(z / H)^{3}+0.4161(z / H)^{2}$ \\
& & & & & $-0.3366(z / H)+0.4789$ \\
$50^{\circ}$ & $70^{\circ}$ & 0.619896 & & $l_{3} / H=-0.1085(z / H)^{3}-0.3546(z / H)^{2}$ \\
\end{tabular}

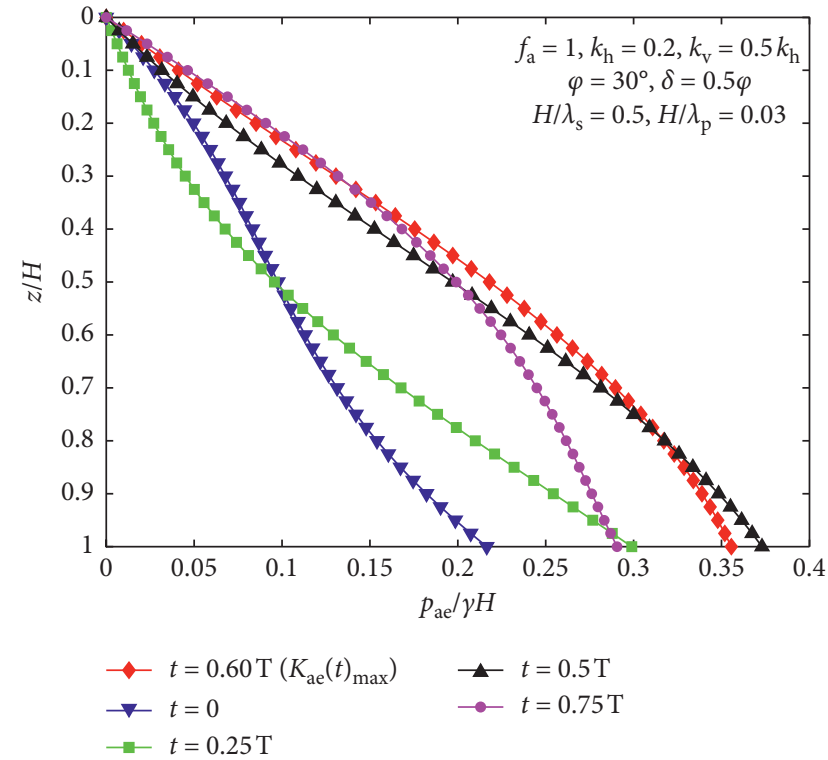

Figure 3: Normalized earth pressure distribution with depth for different values of $t / T$.

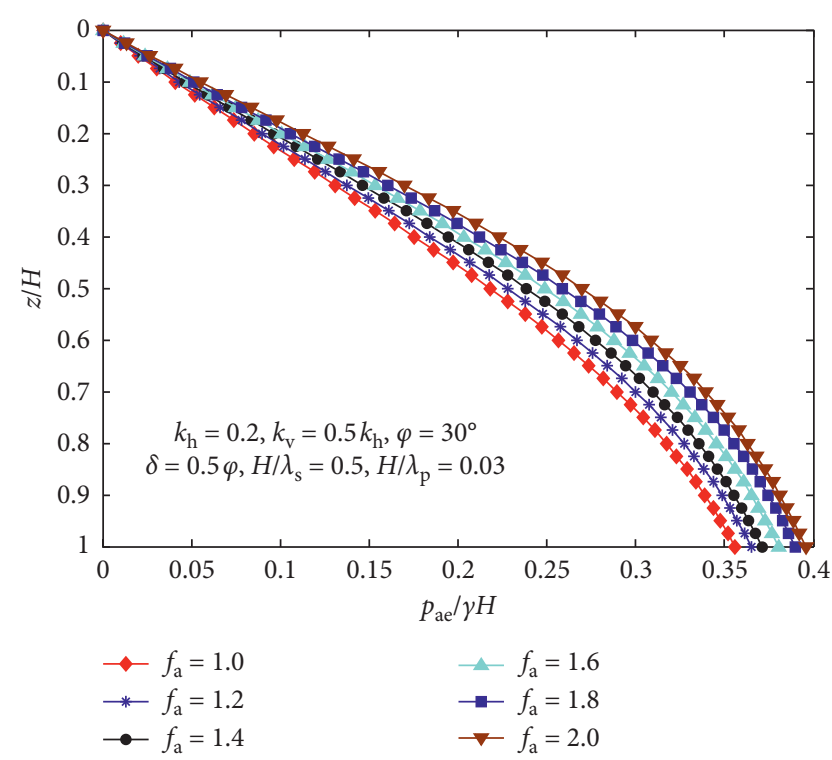

FIgURE 4: Normalized seismic active earth pressure with the change of $f_{\mathrm{a}}$.

method for flat critical failure surface; both values were lower than the total earth thrust calculated by the M-O method. At the bottom of the retaining wall $(z / H=1)$, earth

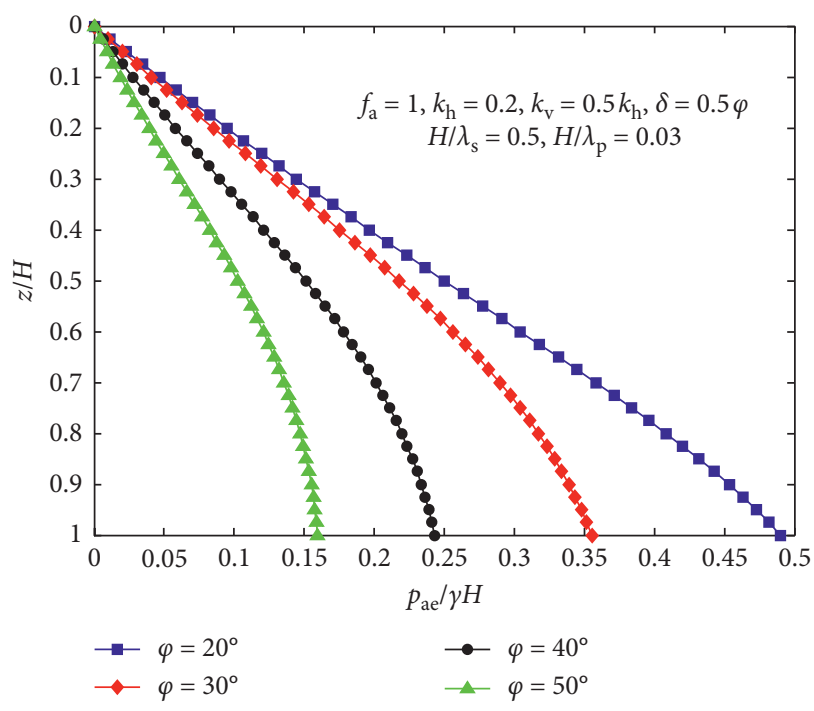

FIGURE 5: Effect of friction angle $\varphi$ on normalized seismic active earth pressure distribution.

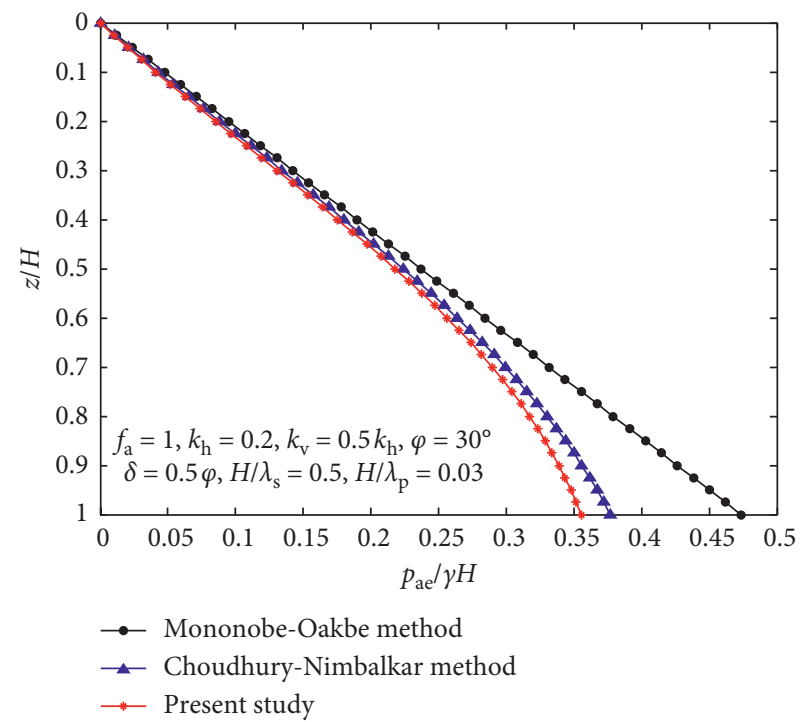

Figure 6: Comparison of typical results of normalized seismic active earth pressure distribution.

pressure calculated by our proposed method had values with magnitudes of about $75 \%$ of those obtained from $\mathrm{M}-\mathrm{O}$ method. It can be seen in Figure 6 that, under the same 
condition, the application point of the resultant earth thrust obtained in this study was higher than those obtained by the other two methods.

\section{Conclusion}

Based on the principles of pseudodynamic method, this study assumed curved critical rupture surface in combination with the logarithmic spiral and straight line for backfill soil. By considering the effects of amplification factor, soil friction angle, soil-wall friction angle, horizontal and vertical seismic acceleration coefficients, and other factors, the present study analyzed the forces acted on soil wedges behind retaining walls. Theoretical equations for total seismic active earth thrust with curved rupture surfaces were derived based on the pseudodynamic method and limit equilibrium theory. The distribution of seismic active earth pressure along the depth of a retaining wall was determined using a mathematical method.

According to the analysis and comparison of effective factors, the following conclusions were obtained:

(i) The distribution of seismic active earth pressure along the depth of a retaining wall was changed with the initial phase change of seismic acceleration, and the total active earth thrust was first increased and then decreased with time during one vibration period.

(ii) The amplification factors had a slight effect on the distribution of seismic active earth pressure and earth pressure distribution curves calculated by different values of this coefficient were almost similar. Higher assumed amplification factors gave higher total earth thrust values.

(iii) The friction angle of soil had the strongest effect on the distribution of seismic active earth pressure, and the calculation error of the proposed method could be very high for improperly selected friction angle values.

(iv) Seismic active earth pressures calculated by the present study were lower than those obtained from the other two classical methods (M-O and C-N).

In general, the assumption of curved critical rupture surface for backfill was more consistent with existing theoretical and experimental results and the calculation method proposed in this study for seismic active earth pressures on retaining walls could be helpful in seismic design.

\section{Nomenclature}

$a_{\mathrm{h}}(z, t)$ : Horizontal acceleration at any depth $z$ and time $t$ $a_{\mathrm{v}}(z, t): \quad$ Vertical acceleration at any depth $z$ and time $t$

$f_{\mathrm{a}}$ : $\quad$ Amplification factor

$g: \quad$ Acceleration due to gravity

$G$ : $\quad$ Shear modulus of the backfill soil

$h$ : $\quad$ Height of the wedge $O C B$ as shown in Figure 1

$H$ : $\quad$ Height of the retaining wall

$k_{\mathrm{h}}, k_{\mathrm{v}}: \quad$ Horizontal and vertical seismic acceleration coefficients $k$ : $\quad$ Parameter that reflects the relationship between $h$ and $H$

$K_{\mathrm{ae}}(t)$ : Pseudodynamic active earth pressure coefficient

$K_{\mathrm{ae}}(t)_{\max }: K_{\mathrm{ae}}(t)$ maximizes at one time $t$

$l_{1}(z)$ : Horizontal length of the wedge OCB at any depth $z$ as shown in Figure 1

$l_{2}(z)$ : Horizontal length of the wedge ODC at any

depth $z$ as shown in Figure 1

$l_{3}(z)$ : Horizontal length of the wedge DAC at any depth $z$ as shown in Figure 1

$m(z)$ : $\quad$ Mass of elemental strip in wedges (related to the abovementioned $l_{1}(z), l_{2}(z)$, and $l_{3}(z)$ )

$p_{\mathrm{ae}}(t)$ : Intensity of seismic active earth pressure

$p_{\mathrm{ae}}(t)_{\max }$ : The intensity of seismic active earth pressure when $K_{\mathrm{ae}}(t)$ maximizes at one time $t$

$P_{\mathrm{ae}}(t)$ : Total seismic active earth pressure

$Q_{\mathrm{h}}$ : $\quad$ Horizontal inertial forces acting on wedges as shown in Figure 1

$Q_{\mathrm{v}}$ : $\quad$ Vertical inertial forces acting on wedges as shown in Figure 1

$r$ : $\quad$ Radius of logarithmic spirals

$t, T, \omega$ : Any time $t$ within the time period $T$ moving at an angular velocity $\omega$

$v_{\mathrm{s}}, v_{\mathrm{p}}: \quad$ Shear and primary wave velocity propagating through the backfill soil

$W$ : Weight of the backfill soil wedges as shown in Figure 1

$\alpha: \quad$ Angle of the failure plane (BC) with the horizontal ground surface

$\delta: \quad$ Soil-wall interface friction angle

$\varphi: \quad$ Friction angle of the backfill soil

$\lambda_{\mathrm{s}}, \lambda_{\mathrm{p}}$ : Wavelength of the vertically propagating shear and primary waves through backfill soil $\left(\lambda_{\mathrm{s}}=v_{\mathrm{s}} \cdot T, \lambda_{\mathrm{p}}=v_{\mathrm{p}} \cdot T\right)$

$\gamma: \quad$ Unit weight of backfill soil.

\section{Data Availability}

There are no actual measurement data in the article.

\section{Conflicts of Interest}

The authors declare that they have no conflicts of interest.

\section{Acknowledgments}

This work was supported by the National Natural Science Foundation of China (grant no. 41772275) and the Fundamental Research Funds for the Central Universities (grant no. 300102268203).

\section{References}

[1] S. Okabe, "General theory of earth pressure and seismic stability of retaining wall and dam," Journal of the Japanese Society of Civil Engineers, vol. 10, no. 5, pp. 1277-1323, 1924.

[2] N. Mononobe and H. Matsuo, "On the determination of earth pressures during earthquakes," in Proceedings of the World Engineering Congress, Paper No. 388, vol. 9, pp. 177-185, 
International Association for Earthquake Engineering, Tokyo, Japan, 1929.

[3] R. S. Steedman and X. Zeng, "The influence of phase on the calculation of pseudo-static earth pressure on a retaining wall," Géotechnique, vol. 40, no. 1, pp. 103-112, 1990.

[4] X. Zeng and R. S. Steedman, "On the behaviour of quay walls in earthquakes," Géotechnique, vol. 43, no. 3, pp. 417-431, 1993.

[5] D. Choudhury and S. S. Nimbalkar, "Pseudo-dynamic approach of seismic active earth pressure behind retaining wall," Geotechnical and Geological Engineering, vol. 24, no. 5, pp. 1103-1113, 2006.

[6] S. Ghosh, "Pseudo-dynamic active force and pressure behind battered retaining wall supporting inclined backfill," Soil Dynamics and Earthquake Engineering, vol. 30, no. 11, pp. 1226-1232, 2010.

[7] S. Ghosh and R. P. Sharma, "Pseudo-dynamic evaluation of passive response on the back of a retaining wall supportingc$\Phi$ backfill," Geomechanics and Geoengineering, vol. 7, no. 2, pp. 115-121, 2012.

[8] I. Bellezza, "Seismic active earth pressure on walls using a new pseudo-dynamic approach," Geotechnical and Geological Engineering, vol. 33, no. 4, pp. 795-812, 2015.

[9] A. D. Maskar, S. N. Madhekar, and D. R. Phatak, "Redistribution principle approach for evaluation of seismic active earth pressure behind retaining wall," Journal of the Institution of Engineers (India): Series A, vol. 99, no. 1, pp. 79-93, 2017.

[10] B. G. Rajesh and D. Choudhury, "Generalized seismic active thrust on a retaining wall with submerged backfill using a modified pseudodynamic method," International Journal of Geomechanics, vol. 17, no. 3, Article ID 06016023, 2017.

[11] K. Terzaghi, K. P. R. B. Terzaghi, and K. P. R. B. Terzaghi, Theoretical Soil Mechanics, John Wiley \& Sons, Hoboken, NJ, USA, 1965.

[12] J. Kumar, "Seismic passive earth pressure coefficients for sands," Canadian Geotechnical Journal, vol. 38, no. 4, pp. 876-881, 2001.

[13] A.-H. Soubra, "Static and seismic passive earth pressure coefficients on rigid retaining structures," Canadian Geotechnical Journal, vol. 37, no. 2, pp. 463-478, 2000.

[14] D. Choudhury, T. Sitharam, and S. K. Rao, "Seismic design of earth-retaining structures and foundations," Current Science, vol. 87, no. 10, pp. 1417-1425, 2004.

[15] K. S. Subba Rao and D. Choudhury, "Seismic passive earth pressures in soils," Journal of Geotechnical and Geoenvironmental Engineering, vol. 131, no. 1, pp. 131-135, 2005.

[16] B. M. Basha and G. L. S. Babu, "Computation of sliding displacements of bridge abutments by pseudo-dynamic method," Soil Dynamics and Earthquake Engineering, vol. 29, no. 1, pp. 103-120, 2009.

[17] B. M. Basha and S. G. Babu, "Seismic stability analysis of reinforced soil structures using pseudo-static method," in Proceedings of the 17th International Conference on Soil Mechanics and Geotechnical Engineering, vol. 1, pp. 13891399, Alexandria, Egypt, October 2009.

[18] B. M. Basha and G. L. S. Babu, "Reliability assessment of internal stability of reinforced soil structures: a pseudo-dynamic approach," Soil Dynamics \& Earthquake Engineering, vol. 30, no. 5, pp. 336-353, 2010.

[19] B. M. Basha and G. L. S. Babu, "Seismic rotational displacements of gravity walls by pseudodynamic method with curved rupture surface," International Journal of Geomechanics, vol. 10, no. 3, pp. 93-105, 2010.
[20] S.-Y. Xu, A. Shamsabadi, and E. Taciroglu, "Evaluation of active and passive seismic earth pressures considering internal friction and cohesion," Soil Dynamics and Earthquake Engineering, vol. 70, pp. 30-47, 2015.

[21] G. Santhoshkumar, P. Ghosh, and A. Murakami, "Seismic active resistance of a tilted cantilever retaining wall considering adaptive failure mechanism," International Journal of Geomechanics, vol. 19, no. 8, Article ID 04019086, 2019.

[22] MathWorks, MATLAB [Computer Software], MathWorks, Natick, MA, USA, 2010. 